\title{
Discussion about the Application of MOOC in Engineering Education
}

\author{
Ying-Yan Luan ${ }^{1, a}$, Rui He ${ }^{1, b,{ }^{*}}$, Dai Gao ${ }^{1, c}$ \\ ${ }^{1}$ P.O.Box 450, Harbin Institute of Technology, No. 92, Xidazhijie Street, Harbin, P.R.China \\ aluanyy@hit.edu.cn, bherui@hit.edu.cn, cd.gao@hit.edu.cn \\ ${ }^{*}$ Corresponding author
}

Keywords: MOOC, Engineering education, Teaching method research.

\begin{abstract}
As a popular teaching method, the advantages and disadvantages of Massive Open Online Courses (MOOC) are analyzed in this paper. It is dedicated that MOOC could bring the reformation to higher education instead of taking the place of universities. The knowledge hierarchy and structure characteristics of the engineering courses are analyzed, therefore the possibility of applying MOOC in engineering education is deduced based on the prior experience of MOOC. A new thought of engineering education is provided by proposing a feasible plan for the implementation of MOOC in the engineering courses.
\end{abstract}

\section{Introduction}

MOOC, which stands for Massive Open Online Courses, was appeared in American universities. In 2012, three education online platforms, Udacity, Coursera and ed, were created by Stanford University, MIT and Harvard university respectively. And they have attracted millions of registered user by now. Therefore, the year 2012 is called as "the first year of MOOC" by The New York Times [1] to describe the rapid development of MOOC. Someone believe that the furious spread of MOOC will bring reforms and challenges to the higher education, meanwhile there accompany with opposite sounds. This paper tries to analyze the characteristics and attractive features of MOOC, then to discuss the application of MOOC in engineering courses.

\section{Characteristics of MOOC}

Large-scale, open, low threshold characteristics are the significant features and advantages of MOOC. High quality teaching resources sharing will be inevitable, the learners can choose courses based on their specialties and needs. Learners get benefits of MOOC which include the broad learning space, flexible time schedule and chance to get involved with famous teachers

\section{The Integrity of the Content}

Different from putting the teaching materials on internet, the lecturers are responsible during the whole teaching processes. MOOC includes not only the teaching videos, lecture materials and exercises, but also interactions of teacher and leaner, such as practice feedback, issue discussions, BBS activities, quiz and exam, and even granting certificates [2]. Thus, those activities cover the complete teaching, learning and training processes.

\section{Professional Production}

When making the MOOC materials, professional technology development teams and content providers are involved to improve the quality and enrich the contents. Meanwhile, ordinary classrooms are no longer the only choice of teaching place. The teaching activities can be hold in the workshops or laboratories also, according to the practical needs, hence to make the teaching processes more vivid, interesting and close to real. 


\section{The Decomposing of Knowledge}

Short videos with the corresponding real-time online tests, teachers explore knowledge by learning contents or study time of the courses by designing teaching style. The course is divided into several units with a number of knowledge points, 10 to 15 minutes of videos are designed by using advanced media tools according to vivid teaching design. Quizzes and tests are designed corresponding with the micro courses. After studying in phases, interactive discussions and BBS are using to help learners to thoroughly digest the knowledge they learned.

\section{Learners' Autonomy}

In MOOC system, learners can control their own learning progress according to their own personalized learning plan. By using self-management, they can master the knowledge step by step. Combining MOOC with offline education, and using theory of the Flipped Class Model [3], the learning process could be divided into two parts. First, students watch the MOOC videos by using functions of replay, pause and repetition. Then through discussion with the teacher, they can understand and master the knowledge. This model transfer the traditional style which teach with the new information into autonomous learning. Therefore, interactions on the class will be deep among the students and teacher. The students are no longer passive information receivers, teachers are no longer one way information givers, and the learning pattern is completely reformed.

\section{The Diversity of Assessments}

Different from the traditional assessments of "homework plus test", the assessments methods in MOOC system are mostly based on the internet. Online evaluation can give full play to the network advantage. There is a variety of evaluation methods. Individual learners submit homework, perform tests, and get on-line evaluations. MOOC participants can also establish online communities to carry on course and issue discussions, in those academic forums, users give assessment to each other. And course teaching teams can perform comprehensive tests and evaluations on learners.

\section{The Dividing of Teaching and Learning}

The essence of MOOC is a kind of online generated courses based on pure information technology. The teaching designs are made by teachers in charge of the courses, information and the other links of MOOC are fulfilled by content producing teams. In this way, non-individualization general templates of the contents' arrangement would appeared inevitable. Curriculum of video production and homework arrangement would be a standardized format undoubtedly. The process of teaching and learning among teachers and students is communicated on the internet, without face to face interactions. Teachers could not obtain students' attitudes and reactions, which plays a very important role in teaching and learning process. Considering the nature of education, teaching and learning are combining into a complete system that cannot be divided. Teaching knowledge is just a part of a teacher's work, meanwhile reassure is also important. MOOC education changes teaching process into knowledge information transforming process, which brings huge challenge to the core value of education[4].

\section{Analysis of the Characteristics of Engineering Course}

Engineering course always with unique characteristics in electronic sciences, engineering disciplines or the construction majors. The most significant feature is the engineering practice, in which design and production are the main goals of the projects. Meanwhile, the appearance of cut-edge techniques take continuous development and changes to engineering courses. From the view of training target, the necessary qualities of engineering talents are the practical ability and innovation ability. Considering the courses themselves, knowledge points are connected tightly, and specialized courses dependent on prerequisite courses. Compared with the social sciences, the content of the course is dull which brings great difficulty to the teaching design.

Take Mechanical discipline for instance, the product design and parts processing is the main research subjects, talents training should focus on engineering practice ability and innovation 
capability. Curriculum setting are based on each course, theoretical teaching is just one part, the experiment teaching is indispensable and project design throughout the period.

The traditional main courses such as mechanical drawing describe the design ideas by using the projection theory. It is an introductory course to the engineering design. The basic question of mechanical processing and the technology concept are introduced during the course. The teaching process includes theory, practice, surveying and mapping. Metallurgical technology courses take parts processing as the main line, and mainly focus on the characteristics of various processing method. The main purpose is to make students grasp the various processing and numerical control machining technology, and ensure that the components' structure design conform to the requirements of the engineering. Mechanical design courses emphasis in terms of intensity and structure design, so operations and course designs are indispensable, They aim at cultivating students' ability in mechanical design. Other basic disciplines related major include basic theory, and accompany with experiments, practices, project designs, etc.

\section{Application and Discussion}

From the analysis above, it is clear to see that there exist a lot of operation and experiment in engineering courses. Practical is a main characteristic of these courses, if MOOC is totally used to teach this kind of courses, it is difficult to achieve the desired effect. However, the idea of MOOC could be used to realize the flipped class model. MOOC could be used as pro-phase theory teaching to enable students to obtain the guidance from experts with rich teaching experience. Personalized design of practice teaching could be used to cultivate students' ability of innovation and practice. Thus, class time could be used to guide, question and answering, discussion. Students could master knowledge through the discussion with teachers or students in the classroom. In this way, passive accept knowledge style has transfer to active thinking, this could help them learn to use theory to solve practical problems. In this way, in the overall design of the course, the traditional curriculum structure may be broken and restructured into theoretical learning, practice teaching, classroom discussion, design, etc.

\section{Theoretical Knowledge Application}

MOOC videos production process including designing, planning, teaching, recording and post production are made by professional team. Places are not limited in classroom and could be in the engineering actual scene. MOOC videos could be produced by cooperation with other universities absorb advantages of each university to create a high-quality curriculum. MOOC videos could also be produced by one university, a series of main course MOOC can be finished by the co-ordination of upper level leadership. MOOC of The content should not invariable, New technology and new ideas should be updated based on their need. Teachers could also recommend learners MOOC fit for them.

\section{Experiment Application}

Experiments seem difficult to be implemented in MOOC because they need to be operated practically. Considering carefully, however, not all of the experiments are unavailable to be held in MOOC, such as computer programming and some computer experiments could take use of MOOC. Furthermore, with the rapidly development of computer technology, virtual reality technology could simulate a number of experiments, This could be a research direction by researchers in this field.

\section{Innovative Collaborative Application}

One of the biggest advantages is online education, thus, by establishing network community based on a subject, carrying out academic forum, learners can communicate and discuss problems without face to face. MOOC Maker should consider how to build the network team and how to guide the exchange direction between learners, this is the essential link of MOOC. 


\section{Previous Work}

As mentioned before, thanks to the advantages of MOOC, our team has begun to make MOOC since 2014. By now, the teaching videos for MOOC have been recorded, and the platform of independent website has been built which including user management, course introduction, curriculum learning, curriculum quiz, teaching discussions. These modules go to the trial run process.

Since 2013, Young teachers applied MOOC style to training the students to take part in the nation advanced map and modeling contest, the effect is significant. The students came from different college and difficulty to find a common time to accept the course. in this case, teacher make and upload videos on the internet. Students teach themselves by watching videos made by teacher, the teacher answer questions one time one week, and gave the students one homework one time a week, one quiz a month. In this way, students get a very high ability on reading professional drawings and can give the 3D models in very short time. In 2014, they obtain the first prize in this contest.

\section{Summary}

The impact of MOOC to engineering education will be enormous, even subversive, it is even predicted by U.S. "National Interest" magazine that a half of the four thou sand universities of the U.S. would disappeared in the coming decades [5]. However, if consider it clearly, the higher education not only teach the knowledge, but also cultivate students' character. MOOC could not take the place of universities, but it bring challenges to the current education model. It is also can say that MOOC propose a new development direction to university direction and higher requirements to the teachers.

\section{Acknowledgment}

This essay is supported by Heilongjiang the 12th Five-Year Plan Higher Education Research Project (14G004), Heilongjiang Higher Education Reforms Project (JG2014010691), and Youth Special Education Research Fund of Harbin Institute of Technology (HIT20140105).

\section{References}

[1] H. Lu, J. Wang, F. Chen.Thinking of medical online education in China under the MOOC fad, Modern Education Science. 4 (2014) 160-175.

[2] X. L. Does MOOC is show window or palace?, China University Education. 5 (2014) 15-18.

[3] J. Zhang, Y. Wang, B. Zhang. Introducing a new teaching model: flipped classroom, Distance Education Journal. 30 (4) (2014) 46-51.

[4] W. Wu. Calm thinking of "MOOC hot", Fu Dan Education Forum. 12 (1) (2014) 10-17.

[5] N. Harden. The end of the university as we know It, The American Interest. 3 (2013) 54-62. 